\title{
Your Mother Tongue Is Helping Me
}

\author{
Dr. Marcia Pinheiro ${ }^{1}$
}

\begin{abstract}
Each language we have on earth seems to possess peculiarities that could bring us a lot of joy if ever correctly isolated, since we could be associating those with skills, and some of those skills might be priceless for those pursuing careers in Science. It is impossible to deny that each people could be described through a set of unique characteristics. Maybe it is time to talk about unique and supplementary skills that come associated with those descriptions because maybe it is time to have our systems turning to the side of perfecting and matching those skills to the point where we can select individuals in a way to optimize the processes involved in the resolution of major human problems, such as crime.
\end{abstract}

Keywords: Language, mother tongue, diversity, multiculturalism, research, culture

\section{INTRODUCTION}

We decided to isolate skills that are frequently needed by the Japanese people because of their choice of language, and we will probably not find much opposition to the claim that they would have to have very well developed drawing skills. Drawing their characters demands patience, firmness, concentration, and spatial vision that are above the usual levels in human kind.

We decided to isolate skills that are frequently needed by the Brazilian people because of the same factor, and we will probably not find much opposition to the claim that they would have to have a very high level of tolerance to emotional disturbances: They can probably deal with noises, and reactions that people cannot normally deal with. With that, they are probably more insensitive, and less empathetic than the rest of human kind.

We decided to isolate skills that are frequently needed by the American people because of the factor we target, and we will again have the situation of probably not finding much opposition to the claim we present: They would have to have a very synthetic, simple, and objective approach to problems.

If we did the same thing to the French people, we would probably say that they are romantic, warm, and into celebrating things that the usual person does not celebrate.

These skills, which appear in association with the language of our birth/upbringing, may dictate our approach to solving problems, so that we could actually be selecting researchers using a criterion that referred to their birth, and upbringing upon knowing what skills the problem we must solve demands.

We are obviously referring to the really spicy part of the problem, so say we have to solve The Liar Paradox once more (Pinheiro [20]). This problem involves face-to-face communication, so that our question would be: What is the language that is associated with best face-to-face communication skills in our chart?

We would then look for languages where the individuals tend to communicate starring at the face of the listener, with maximum amount of observation of the other, so say Portuguese, Brazilian version: Brazilians are used to pay attention to each line of the other person's face as they speak because, first of all, they attempt to detect variations in their mood, tune, and others. People are seen as very explosive, and reactive in their culture, so that all care is not enough. Some can die from being shot by their best friend out of a misunderstanding.

In the case of a problem like The Liar, the people we mention should be the best we can get, so that a researcher who has been raised using the mentioned language is our best bet, a way to optimize the processes of resolution of that problem.

The Liar is also about telling lies, so that a people who pride themselves on best lying could also be the best to talk about lies in general. The people who best lie would have to be the people who have the best actors. We tend to think that those would be The Americans, given the popularity, and the money that are associated with the Hollywoodian movies. Notwithstanding, movies, especially from Hollywood, involve a lot of gadgets and techniques, so that we really have to look for talent in the theatre instead. Theatre is almost like real life, so that if we look for the people who best deceive, who most make others, for instance, help them when they are actually heinous, and deserve no help, we should be able to find our best actors. Some would quickly say that

${ }^{1}$ drmarciapinheiro@gmail.com

DOI: 10.9790/0837-2109022935

www.iosrjournals.org

29 | Page 
those can only be the Africans, given the fact that white people donate tons of money, and other items to them every year, and they don't even live in the same continent, and they do this whilst the whites around them are equally starving, crying, etc., but a large amount of Hollywoodian strategies is used to attract such an amount of inadequate attention to the black peoples, so that that should not count either.

The best deceivers are those who can destroy us in our personal lives even when we are intellectual exponents, so say successfully ruin our perfect careers, bodies, faces, reputation, etc., and get away with all either for eternity or for the longest amount of time we have heard about. We tend to think that those would be the Australians.

To tell the mechanism of the successful lie, the why of the lie, and the effects of the lie, therefore, we should choose an Australian. To talk about what can be extracted of information from face-to-face contact, we should choose a Brazilian.

The Liar obviously involves Logic as well, so that the smallest package would be: Logic, face-to-face communication, and lies.

In terms of Logic, we cannot really go for synthesis, and objectivity, since we also need analysis, and quite a lot of it. To analyse things to best, we need patience, observation, and deep reflection, so that an Asian people should be our best choice, a people who spoke the language that most had of the mentioned skills in their set of associations.

The smallest possible package, in terms of research team, should then be a Brazilian, an Australian, and an Asian.

It sounds odd, does it not? Notwithstanding, it also sounds brilliant, like it suffices that we change the mental paradigms we are used to rely on, that is, that we change the box through which we see this world, and human kind, and it may also sound brilliant.

This paper is basically about how we can start a theory that will help us isolate the skills we currently have in our so diverse race.

\title{
II. DEVELOPMENT
}

Kawagoe [1] makes us notice that some skills would have to be associated with writing in Japanese: memory, perceptual, pattern identification, associative (to associate patterns with mental images, and with other patterns), and so on.

Two extracts (Kawagoe, [1]):

The problem is that drawing from memory or from imagined image is extremely difficult, even for a trained artist.

The leader wrote words on the board like lion, giraffe, elephant, cat, dog, carrot, maple leaf, etc. We had to draw them. Then she had us draw a plant of our choice, step-by-step, from seed to the finished product be it fruit or flower. It was a big revelation to realize how much we look, but don't see.

First of all, to be able to learn how to draw the characters, because they are drawings, not our continuous lines forming symbols that we call letters, we have to be able to observe things extremely well: Every stroke matters. There is also Science involved in being able to draw with speed, and still in a manner that one character is not confused with the other. It is difficult to put all the necessary elements together.

Details matter: Whilst in our occidental writing we put a 0 with a badly finished line to the right, and this easily makes us build an A in our mental universe via guessing processes, so that no mistake in interpretation ever happens if we see anything that resembles a circle with anything that resembles a finger to the right, lower part, the same will rarely happen in Japanese.

See:

\author{
Kanji: 安い \\ Meaning: (adj)cheap/inexpensive/peaceful/quiet/gossipy/thoughtless/
}

\section{Kanji: 耳}

Meaning: (n)(1)ear/(2)hearing/(3)edge/crust/

Thinking of the first symbol in the examples we have just presented, it suffices that we are lazy, and basically incline the building when we are drawing the second set, for us to have something that resembles what we have in the first set. Yet, were it our A, we would never have such a problem.

The detail is what matters in their writing, and therefore their attention to those delicate strokes has to be enormous. 
The amount of labour involved in their writing is extraordinary:Observation, attention, precision, and many other skills come together in this one piece of their culture.

When we do dynamic reading, we, occidental people, look for keywords, and other things that escape patterns. The Japanese would have to look for sets of drawings to do the same job. They therefore have a much more refined spatial vision: Whatever involves real-life objects, and synthesis of images should be better grasped by them, not by us.

It is as if their minds are more prepared for the 3D world, so that they should find it easier to deal with Astronomy than with Mathematics whilst we should find the latter easier, as for vast majority. Their results in that piece of Science should also be better than ours, like we would expect The Japanese to find way more new stars than The Occidental Peoples. predictable.

It is possible that we have never had such studies happening before, but the results could be

It is all about training our system (eyes, mind, connection between elements that seem to form an individual entity, etc.).

Brazilian Portuguese is a language that is seen as very musical by most people. See an extract from (Batzarov, [3]):

The phonetic system of the Portuguese language is extremely rich.In standard Portuguese it consists of 9 simple vowels, 5 nasalized vowels, 2 semivowels, 25 simple diphthongs, 4 nasalized diphthongs, 5 simple triphthongs, 4 nasalized triphthongs, 21 consonants, or a total of 75 entities. Unstressed vowels are reduced. The nasalization is indicated in the orthography by $\boldsymbol{m}$ or $\boldsymbol{n}$ following the vowel (e.g., sim yes, bem well) or by the use of a tilde ( ) over the vowel (mão hand, nação nation).

As we see in (Colleen, [4]), the English language has 12 vowels, like in total, and therefore 4 less than what we see in the Portuguese language, and 8 diphthongs, and that is 21 less than what we see in the Portuguese language. We have 24 consonants in the English language, and only 21 in the Portuguese language, as we see in the extract above.

Lingholic [5] lets us know that whilst the Portuguese language has about 390,000 words in use, the English language has about 171,476, so that the Portuguese language tends to specify things much more than the English language, and therefore should be more adequate for Science. We have decided to adopt English as our official language after studying things very well, so that we can use the information acquired in the following sense: People who were born speaking Portuguese would have a better understanding of Science than people who were born speaking English, this in average, and therefore they would have more power of analysing, and understanding things, what should make them superior in disciplines like Logic.

The extraordinary difference in cardinality between the two languages will however give fewer points to those born speaking Portuguese in terms of adaptation, and flexibility: When you are obliged to attach more senses to a sigmatoid ${ }^{2}$, you have to make your mind become more adaptable to new things, is it not?

Joshi \& Aaron [7] let us know that French is a romance language. See:

French is a Romance language, and, as such, it has inherited a number of features from the originalLatin, in the same way as Italian, Portuguese, and Rumanian have.

Another extract of their book:

In the latter two languages (Italian and Spanish), the inflections are denoted by phonograms, andthe information is so transparent that, in these two languages, there is no need to add the corresponding pronouns.

In French, on the contrary, there obviously exists a high level of homophony among the various oral forms.

So, in this passage, Joshi and Aaron (2013, [7]) are letting us know that it may take longer for us to say things in French than it would take for us to say things in Italian or Spanish.

Morwood\& Warman [8] let us know that

\begin{tabular}{lll}
${ }^{2}$ (Pinheiro, [6]) & & \\
\hline DOI: $10.9790 / 0837-2109022935$ & www.iosrjournals.org & 31 Page
\end{tabular}


We call Italian, Spanish, French, Portuguese and RomanianRomancelanguages because they were originally spoken bythe Romans. The word romance also has other meaningswhich developed over time in three stages:

1 It was used to describe stories written in one of theselanguages about knights and their adventures.

2 This led to its meaning any story full of wonderful andextraordinary happenings.

3 From that it came to mean the sort of book which dealswith love in a sentimental way, or simply to mean a loveaffair itself.

We then understand that French is called Romance language, but the connection between the sigmatoidromance, and what we nowadays know as its sense appeared a bit later due to events that connect to writing.

It could then be that we had the statement, that French is the language of romance, from their writings, but that does not seem to be what is there.

Chatel [9] writes the following:

One Hour Translation, the largest online translation agency, surveyed 1,000 people in 10 different developed countries to see what language was mostly associated with romance. It was, to no one's surprise, French.

Today Translations [10] tells us that

The survey was conducted by London-based Today Translations which polled over 320 of its linguists.

After Italian, they found the second-most romantic language was French, which was way ahead of Spanish and English in joint third place.

Vanessa [11] says that (two extracts)

Of the 8,615 people involved in the online poll conducted by Expedia, 87 per cent said that learning a second language in school should be made compulsory.

Australians also confirmed - French is the most romantic language, with 61 per cent vouching for the notion according to the survey.

With this, French would have to be the most romantic language in the world.

What romantic people do not have is objectivity, right? background.

In this case, there should not be much that would not do better with somebody from another cultural

We must observe, however, that our studies are focusing on only one aspect of the human being, which is their mother tongue. And we are also referring to recruiting people for research. We are talking about cultural backgrounds that could be most likely to lead to the best solution of the problem we have at hand in terms of time, and brilliance.

Mathematics would have to be one of the most objective pieces of Science of all, and Allen [12] lets us know that fifteen of the top sixty greatest mathematicians of all times were French.

That is pretty good, considering that we have 6,909 different languages on earth (Anderson, [13]).

Amongst those top sixty there is not even one who speaks Portuguese, so that there must be other factors that impact on research outcomes, and are way more relevant than mother tongue.

Maybe culture leads to inhibition or incapacity of participating in research endeavours. For instance, Brazil lacks support in all senses for researchers/academics, and plenty of PhDs end up with a totally mechanical job (Pinheiro, [14]).

The sociological structure of the countries we talk about would have to matter quite a lot, so that it is possible that even though the brightest people on earth in a certain discipline should come from cultures where they speak Portuguese, those cultures do not provide adequate support. As a consequence, the people who are part of the peoples that have those cultures experience unimaginable difficulties when trying to enter Academia.

Sometimes culture destroys researchers. Brazil has lost a second load of space scientists recentlybecause of their management. They all died once more: More than 20 of them each time (D'Alama, [15]).We ourselves suffer atrocity since at most 2001, and all the problems that we have that relate to our academic career are rooted in Brazil/Brazilian people, this since at most 1999 (Pinheiro, [16]). 
In this way, not only the sociological, educational, political, and social structures get on the way of those who are really good at research in the countries where they speak the languages that most favour certain pieces of Science, but there is also a criminal factor that is undeniable.

Once we watched a scientist on TV in Brazil: He had invented a car that moved by water. All disappeared almost next day, and never anymore appeared. We actually find nothing about that on the Internet nowadays.

Another oneinvented foam that dissolved much quicker in the environment, many fewer years, and nobody cared about his research after it was on the news.

With this, they may be brilliant, just like us, but there is an enormous difficulty involved in that brilliance being acknowledged by others for one reason or another.

We would have scored more papers than Poincare by the age of thirty years old if we had never suffered crime, believe it or not. It would have been about 800 papers in our own name, exclusively in our name.

Lots of people, from several cultural backgrounds, are part of the atrocities we endure, not only The Brazilians. There is then a world interest in keeping Brazilian people mediocre in what comes to Science, we believe. Maybe the same sort of problem happens in all cultures where they have Portuguese as their mother tongue, what then explains the statistics involved.

We would like to be involved in research at most by college time, when we started having contact with professional researchers. That was 1984. We could only start attending environments where they do research in 1986, and, even so, because we were lucky to study in a privileged school where the female teacher bothered telling us about IMPA. Wewould never find out about them otherwise.

We were invited to do professional research with our professor during our undergraduate. That was our Statistics professor. The problem was that no funds were available, and it was Statistics, when we preferred Mathematics. Our upbringing, without any contact with professional researchers in our household, our personal culture, acquired also from being raised by those people, and several other factors led us to reject the offer of our good professor. It was perhaps our third year at the university. That would then have been 1990. Only here you can see how many years have been wasted: 6 up to now.

We only started in professional research in 2000, thanks to Australia, and a book that we read about Andrew Wiles and his finding. That was 16 years after what we would have wanted to be our starting date in professional research. Even so, we only did that for experiencing several things that are atypical, one of them being the death of our father, and inheriting a real estate property that we could sell.

We suffer the heaviest crimes ever since our first striking finding, which happened in that year, of 2000. It is a true miracle that we have succeeded in publishing anything at all.

The vast majority of the crimes we suffer in Academia since 2000 originate in Brazil. The heaviest ones are caused by our own relatives.

We are lucky to be alive, walking, talking, and thinking by now, believe it or not.

The score of 800 papers was reached by using our achievements that far, in that 2002, first semester, as a basis. And we counted from 2000 onward. Imagine if we ever had a fair chance in life, and had started doing professional research in 1984 ?

We believe that is what is making our predictions, based on mother tongue, not be compatible with the historical results in research, to be sincere.

We think we are sure we are the most unlikely person in terms of suffering crime in First World, or even in the last, so imagine the rest.

As a consequence of the crimes that we suffer, Prof.GermanusStrazzeri, who was also about 30 yo, starting career in research, slow producer, but innovator, was assassinated, so that we now have another promising researcher from Brazil who could not be counted amongst the greatest researchers because of crime.

The official cause of the death was heart attack, but we know that it was a criminal heart attack, which was probably caused by drugs in his water, and this all would have happened at the university, during his shift.

With this, it is not possible to have reliable statistics over how many of the so few who manage to get an academic position in Brazilgot to be assassinated.

We then understand how even computing abnormal events that lead to the individual not being able to fulfil their potential in Academia is an impossible task.

DOI: $10.9790 / 0837-2109022935 \quad$ www.iosrjournals.org 33 |Page


Africa is another place where they speak Portuguese in a few locations. The levels of misery are so high that some cannot eat when little.

Portugal is a First World Country, so that we could have some Portuguese people appearing as greatest researchers, but we don't. The reasons might be the same as those we presented when it came to our case: upbringing culture, sociological, and educational structures, etc.

Japan is a First World Country, and U.S. News [17] brings its university as $24^{\text {th }}$ in the list of best universities for Space Science. We observe, however, that Japan has recently been the victim of several tsunamis (Oskin, [19]): That could explain the difficulties with ranking highest.

In Portugal, the culture would have to be sexism in Science, just like in Brazil, Africa, and China, which are places that contain peoples whose mother tongue is Portuguese. Just this fact excludes $50 \%$ of their people from the universe of those who could be on top. We observe that we were more meaningful than every male ever alive, considering males who were born in Brazil, in Philosophy, and Mathematics before we were attacked. We are a woman.

We would absolutely never succeed in doing research or in starting in it in Brazil because of the so many structural difficulties, including highest levels of sexism, especially when it comes to publication, and access to basic information, and resources. The places we mentioned are the main places where they speak Portuguese, and, once more, $50 \%$ of their peoples would be excluded by default from the universe that could figure in the list of greatest.

Egee [18] tells us that one out of ten most influential psychiatrists are French.

We do find an impressive number of Americans there, but Americans are raised in a romantic culture, full of those movies, and series that inspire romance, so that they could be above the French because of being moulded by their culture to be more sensitive.

Yet, compared to those who speak Portuguese, and Japanese, The French are infinitely better on this item, as expected.

\section{CONCLUSION}

The mother tongue seems to have a very good chance of determining who we will be in research if the educational/political structure is the same for all involved.

Some factors seem to be decisive to decrease potential, such as sexism, educational structure, culture, and criminal rates.

The mother tongue that presents more discrepancy in terms of prediction, and reality seems to be associated with societies where there is institutional, and governmental crime to exclude women from the publication environment in Science.

We would expect France, and Japan not to suffer from these evils for a few years now. Japan, however, had the highest levels of oppression in terms of women for a long period of the human history: Their women had to dress in a particular way, and had to wear shoes that destroyed or impaired their feet.

Japan suffers natural tragedies for a long time, so that those also explain why they are not yet figuring at the top of the list of the greatest in Space Science.

Even though we only have one in ten of the most influential psychiatrists being bornin France, that is still way more than those who speak Portuguese or Japanese.

Those who speak English seem to be in outstanding advantage there. The Americans could be in advantage because their culture is devoted to exploring romance in movies, series, magazines, etc. With this, they end up becoming even more romantic than the French, whose mother tongue should be a synonym for romance. Images usually impact more on the human brain than words.

It seems to us, in conclusion, that we can make a scientific association between the innate talents of the individual in terms of research, and their mother tongue.

More refined studies are necessary to prove these points, so say studies involving psychometrics, but it seems that there is a strong possibility that if we study mother tongue, and its association with research outcomes or thinking processes, we will reach the conclusion that it is wise basing our selection of personnel on the mother tongue when it comes to specific projects.

It also seems to be true that each mother tongue connects to a set of special, and unique, skills.

We have more than 6,000 languages in human kind (Anderson, [13]). 


\section{REFERENCES}

[1] Kawagoe, A. (2016). Education in Japan Community Blog. Retrieved August 4, 2016, from https://educationinjapan.wordpress.com/education-system-in-japan-general/thoughts-on-art-educationthe-importance-of-learning-to-draw/

[2] Yoshida Institute. (2016). Retrieved August 4, 2016, from http://www.yosida.com/en/kanji.php?level=5\&page=2

[3] Batzarov, Z. (2016). Portuguese Language. Retrieved August 5, 2016, from http://www.orbilat.com/Languages/Portuguese/Portuguese.html

[4] Colleen. (2013). Welcome to Kindergarten. Retrieved August 5, 2016, from https://potentialpolyglot.wordpress.com/2013/06/28/welcome-to-kindergarten/

[5] Lingholic. (2016). How many words do I need to know? The 95/5 rule in language learning, Part 2/2. Retrieved from http://www.lingholic.com/how-many-words-do-i-need-to-know-the-955-rule-inlanguage-learning-part-2/

[6] Pinheiro, M. R. (2015). Words for Science. Indian Journal of Applied Research, 5(5), 19-22. Retrieved from https://www.worldwidejournals.com/ijar/articles.php?val=NjQ0MQ==\&b1=853\&k=214

[7] Joshi, R. M., \& Aaron, P. G. (2013). Handbook of Orthography and Literacy. Routledge. Retrieved from https://books.google.com.au/books?id=14HE-9wuk-

YC\&pg=PT181\&lpg=PT181\&dq=\%22french+language+is+more $\% 22 \&$ source=bl\&ots=-qOnSK10p\&sig=OtxwZsSWOEIPxAP7DvtUxU1yL0s\&hl=en\&sa=X\&ved=0ahUKEwiyrfX7ia_OAhWE7RQ KHahYCcUQ6AEINDAF\#v=onepage \&q=\%22french language is more $\% 22 \& \mathrm{f}=$ false

[8] Morwood, J., \& Warman, M. (1990). Our Greek and Latin Roots. Cambridge University Press. Retrieved from

http://education.cambridge.org/media/577331/our_greek_and_latin_roots_second_edition cambridg e_education__cambridge_university_press_samples.pdf

[9] Chatel, A. (2016). This Is The Most Romantic Language. Retrieved August 7, 2016, from http://www.bustle.com/articles/140507-this-is-the-most-romantic-language

[10] Today Translations. (2010). Is this the world's most romantic word? Retrieved August 7, 2016, from https://www.todaytranslations.com/news/is-this-the-worlds-most-romantic-word

[11] Vanessa. (2008). French is the most romantic language - so why not learn French in France? Retrieved August 7, 2016, from https://www.golearnto.com/travelblog/index.php/2008/11/02/french-is-the-mostromantic-language-so-why-not-learn-french-in-france/

[12] Allen, J. D. (1998). The Hundred Greatest Mathematicians of the Past. Retrieved August 7, 2016, from http://fabpedigree.com/james/mathmen.htm

[13] Anderson, S. R. (2012). How many languages are there in the world? Retrieved August 7, 2016, from http://www.linguisticsociety.org/content/how-many-languages-are-there-world

[14] Pinheiro, M. R. (2013). Full Slavery Means Having at Most Two Choices of Action. Retrieved August 7 , 2016, from http://humanrightseverywhere.blogspot.com.au/2013/11/full-slavery-means-having-at-mosttwo.html

[15] D’Alama, L. (2003). Tragédia em Alcântara faz dez anos e Brasil ainda sonha em lançar foguete. Retrieved August 7, 2016, from http://g1.globo.com/ciencia-e-saude/noticia/2013/08/tragedia-emalcantara-faz-dez-anos-e-brasil-ainda-sonha-em-lancar-foguete.html

[16] Pinheiro, M. (2016). Institutional and Governmental Crimes and Our Chances in Democracy, 21st Century. $\quad$ Retrieved August $\quad 7, \quad$ from http://humanrightseverywhere.blogspot.com.au/2016/07/institutional-and-governmental-crimes.html

[17] U.S. News \& World Report LP. (2016). Best Global Universities for Space Science. Retrieved August 7 , 2016, from http://www.usnews.com/education/best-global-universities/space-science?page=3

[18] Egee. (2010). Top 10 Most Influential Psychiatrists. Retrieved August 8, 2016, from http://listverse.com/2010/07/21/top-10-most-influential-psychologists/

[19] Oskin, B. (2015). Japan Earthquake \& Tsunami of 2011: Facts and Information. Retrieved August 8, 2016, from http://www.livescience.com/39110-japan-2011-earthquake-tsunami-facts.html

[20] Pinheiro, M. R. (2012). Concerning the Solution to the Liar Paradox. E-Logos, 21, 14. Retrieved from www.academia.edu/9787988/Solution_to_the_Liar_Paradox 